\title{
WOMEN AND MINORITIES IN COMPUTER SCIENCE MAJORS: RESULTS ON BARRIERS FROM INTERVIEWS AND A SURVEY
}

\author{
Skyler J. Bock, Washburn University, skyler.bock@washburn.edu \\ Lindsay J. Taylor, Washburn University, lindsay.taylor1@washburn.edu \\ Zachary E. Phillips, Washburn University, zachary.phillips@washburn.edu \\ Dr.Wenying Sun, Washburn University,nan.sun@washburn.edu
}

\begin{abstract}
In this research we investigate why women and minorities are underrepresented in the computer science major. We would like to find out the barriers that are keeping women and minorities from pursuing computer science degrees. This paper reports the results from three studies: analysis of the Taulbee Survey data, interviews with high school and college students, and a random survey of college students. We used the Taulbee Survey to analyze the numbers of women and minorities in computer science bachelor degrees. We used the interviews to identify barriers that keep these students from pursuing the computer science degrees, and we used the surveys to gain information on the effects of each of the barriers we identified. From the interviews we gathered that the main reason the high school and college students weren't pursuing the computer science degree was a lack of interest in the degree. For women, we found perception that computer science is better suited for men as a significant barrier. For minorities (black and Hispanic), lack of computer experience and the perception that computer science is for geeks and nerds are the two significant barriers.
\end{abstract}

Keywords: Women, Minorities, Computer Science, Barriers

\section{INTRODUCTION}

For the past ten years, computer science has been a degree that has primarily been obtained by white men. It is a degree that has several typecasts against it and that has not been diverse with respect to other races and women. Women accounted for only 12 percent of undergraduate degrees in computer science and engineering in the United States and Canada granted in 2006-2007 by Ph.D.-granting institutions, down from 19 percent in 2001-2002 [15]. Many computer science departments report that women now make up less than 10 percent of the newest undergraduates [15]. Consequentially, the information technology industry has a spotty record of hiring Black and Hispanic workers. Hispanic workers were 15 percent of the labor force in 2011 and Black workers comprised 10.8 percent of the labor force and only 5.7 percent of professionals in computer and mathematical occupations are of Hispanic descent and only 6.9 percent are Black [7].

Previous studies that we have researched have not covered a broad range of people when it comes to computer science. Several studies have been done over the underrepresentation of women in computer science fields of study and careers $[15,9,13]$. The same can also be said for the amount of studies done over minorities in computer science. Both have not been combined, from what we have seen, into one research project to identify any related barriers between the two that prevent them from entering the field.

Our research goal is to identify the barriers that keep women and minorities from entering the computer science field. These are three research questions we would like to answer: 1) What barriers prevent women from joining computer science? 2) What barriers prevent other races from joining computer science? 3) And what are the common barriers between the two? In order to answer these research questions, we have conducted three studies. Our first study was over the previous research that has been acquired over the past few decades to give us an understanding of the current situation and to identify barriers. After that, each member of our group conducted interviews with individuals to pinpoint any additional barriers we didn't find from previous research. Then, we contacted our target groups to take surveys to identify the key barriers that prevented women and minorities from entering the computer science field.

The rest of the paper is divided into several sections to show the steps of research we took. Our Literature Review collected facts and prior knowledge about this issue. Our Methodology shows how we conducted the studies. The Results section shows all the collected data from our studies. The Discussion segment talks about our findings from 


\section{Issues in Information Systems \\ Volume 14, Issue 1, pp.143-152, 2013}

previous research, the interviews, and our survey results. The Conclusion shows what our findings point to on this issue.

\section{LITERATURE REVIEW}

\section{Facts}

In $200817 \%$ of AP computer science test-takers were women, although women represented 55\% of all AP testtakers [5, 9]. In 2011 19\% of AP Computer Science test-takers were female [11]. The number is rising slowly but still remains low in the total amount of AP test-takers. In 2010 women earned 18\% of the bachelor's degrees awarded in computer science compared to the 37 percent of those degrees awarded to women in 1985 [9]. In 2010 women received $57 \%$ of undergraduate degrees but they only received $18 \%$ of the Computer and Information Sciences undergraduate degrees, and only $14 \%$ of the Computer Science undergraduate degrees at major research universities [11]. Between 2000 and 2011 there was a 79\% decline in the number of first-year undergraduate women interested in majoring in Computer Science [11]. In $201125 \%$ of the computing workforce was female [11].

In 2008784 African Americans took the AP Computer Science test, which accounts for 4\%, although African Americans represented $7 \%$ of all AP test takers [5]. In 2008, 11\% of computer science AP test takers were underrepresented minorities, although underrepresented minorities make up 19\% of all AP test-takers [5]. In 2008, $6.7 \%$ of Computer Science bachelors' degrees were earned by Hispanic/Latinos [13]. African Americans earned 5\% of computer science graduate degrees in 2008 even though they represent $13 \%$ of the US population [13].

\section{Gender}

A barrier that keeps women from pursuing the computer science degree is that it is recognized that women have less prior experience with computers than men do upon entering the computer science degree and often computer science departments favor students with prior computing experience [1, 12, 14]. Another barrier that keeps women from joining the computer science degree is that the computer science professors treat women differently than men [1]. Women also might not join the Computer Science degree because it is male dominated and women perceive that the degree is better suited for males $[10,4]$. Women might not join the computer science major because they think it is too hard $[6,12]$. Women might also have a misconception that the degree is for "hackers", "geeks", and "nerds" [6, 14]. Another barrier is that women might have a perception that the computer science degree only involves programming [12].

\section{Race}

A recent study has found that minority enrollment, success, and retention in CS and IS majors are caused by poor advisement of the majors, lack of experience studying computing prior to college, and lack of exposure to programming [2]. This same study concludes that minorities of higher socio-economic status have higher computer ownership, but they still lack the proper knowledge to select a computing major.

For African Americans, the decision to pursue computing science degrees is dependent on socially constructed factors [3]. Charleston's studies showed that participants had high levels of ambition and self-initiative, but they were not contributing factors to degree attainment. The factors that did contribute to African Americans pursuit of computing degrees were early advanced engagement with computers and computing, technological incubation, rigorous ground in science and mathematics, computing-related cohort building, knowledge of interdisciplinary nature of computer, and multifaceted mentorship [3].

\section{METHODOLOGY}

For our first study we analyzed data from The Computing Research Association's Taulbee Survey. We used the Taulbee surveys data from 1994 to 2011 on the numbers of women, African American and Hispanic students enrolled in Computer Science Bachelor degrees. We used this data to compile a graph showing the evolving trends of the percentage of females in Computer Science Bachelor degrees from 1994 to 2011 . We also made a second graph showing the changing trends of the number of African Americans and Hispanics in Computer Science Bachelor degrees between 1994 and 2011. 


\section{Issues in Information Systems \\ Volume 14, Issue 1, pp.143-152, 2013}

For our second study we interviewed randomly selected people from different groupings that weren't pursuing or weren't planning on pursuing the Computer Science degree. The interviewees were five female high school students, five female college students, four male African Americans and one male Hispanic. We asked the interviewees about why they chose not to pursue Computer Science degrees to try and identify barriers that kept them from joining the major.

For our third study we constructed a survey using SurveyMonkey. The survey asked questions that tried to identify how much impact each of the barriers had on keeping students from joining the Computer Science major. We asked questions about the following barriers: lack of experience with computers, lack of a mentor in Computer Science, Computer Science is for 'geeks' and 'nerds', Computer Science deals mostly with programming, Computer Science is better suited for males, Computer Science is better suited for Caucasians, scholarships are hard to get in Computer Science, Computer Science degrees are too difficult, there aren't available jobs in Computer Science, Computer Science has an imbalance of work and life. We derived most of the questions from previous studies. Also for each category, at least three items/questions were utilized. A copy of the survey is listed in Appendix A.

\section{RESULTS}

\section{Study 1}

In our first study, we looked at past data recorded by the Taulbee survey. Data is available from 1994 to 2011. Graphing the data over each year shows us how race and gender in Computer Science Bachelor degrees has changed. We are omitting non-essential Taulbee survey data from our study as we are only concerned about gender (females) and race (African American and Hispanic).

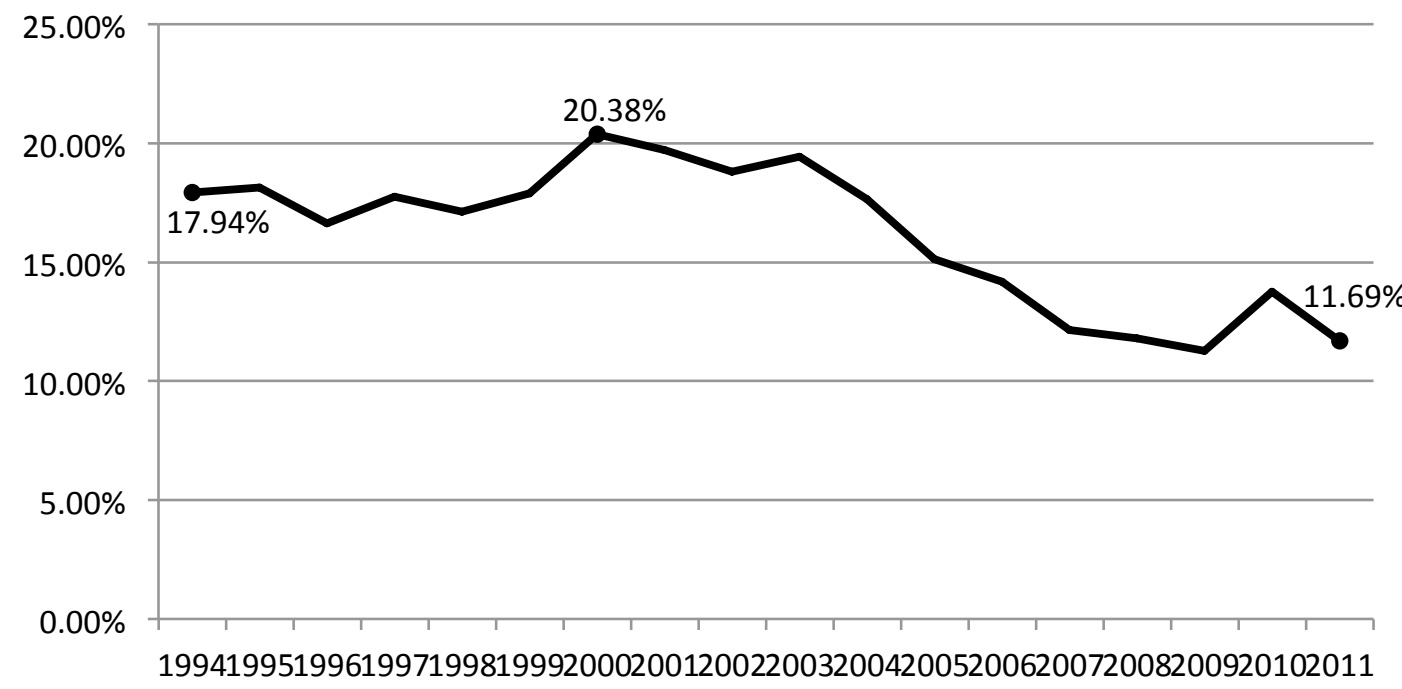

Figure 1 - Female Representation in Computer Science Bachelor Degrees

Figure 1 shows the female representation in Computer Science Bachelor degrees. The peak is in the year 2000, with $20.38 \%$ of Computer Science students being female. In 2011, 11.69\% of Computer Science students were female. This is a 43\% drop in 11 years. The drop isn't as big when you look at where they started in 1994 (17.94\%), but the female representation is declining. The Taulbee survey data shows the low of $11.26 \%$ in 2009. It looks like the 2012 data could be lower as there was a slight spike in the 2010 data that quickly returned to $11.69 \%$ in 2011 . 


\section{Issues in Information Systems}

Volume 14, Issue 1, pp.143-152, 2013

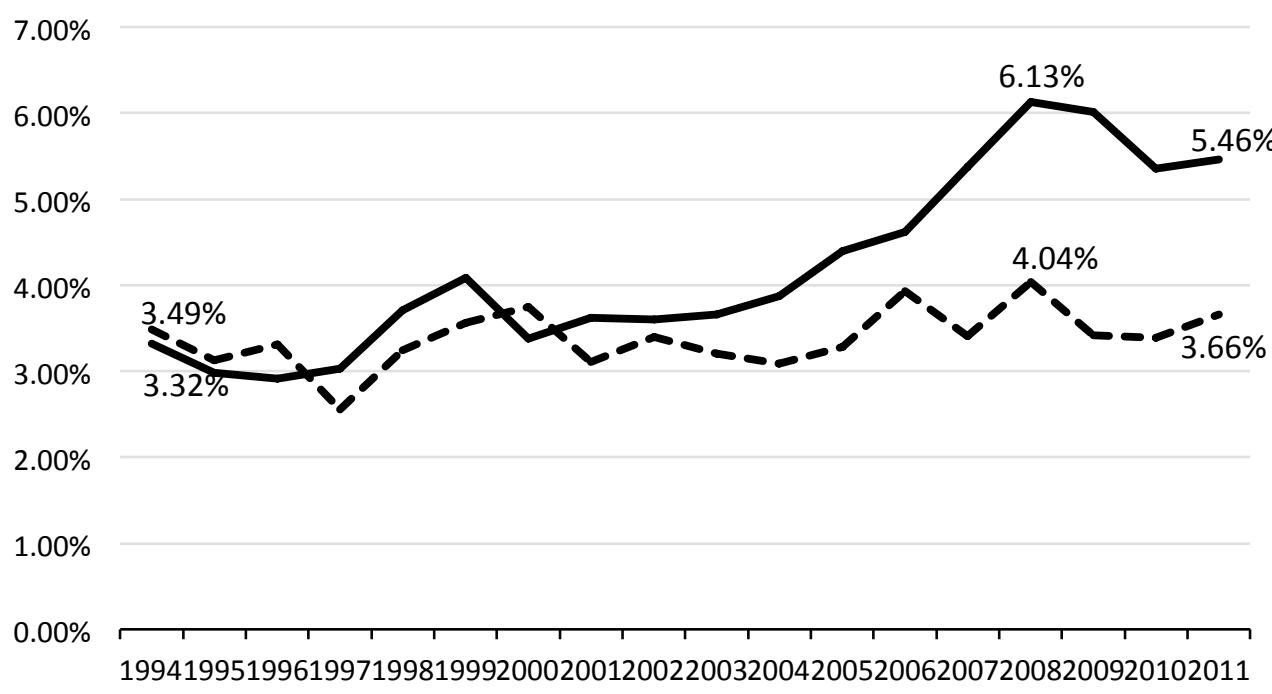

Figure 2 - African American (dashed) and Hispanic (solid) Representation in Computer Science Bachelor Degrees

Figure 2 shows African American (dashed line) and Hispanic (solid line) representation in Computer Science Bachelor degrees. It's interesting to note that Hispanic student population has increased $2.14 \%$ over the years. The peak is $6.13 \%$ in 2008 and then it drops down to $5.46 \%$ where it currently resides. The low for Hispanics was $2.91 \%$ in 1996. After recovering from the low, the population dips again to $3.38 \%$ in 2000. For African Americans, there are some peaks and valleys, but there doesn't seem to be any significant change over the 17 years of data. In 1994, they are at 3.49\% representation and in 2011 they are at 3.66\%. This is just a .17\% increase that's within the margin of error.

The expected representation of these underrepresented groups would be those that mimic the population data. The 2010 US Census data shows $50.8 \%$ of the population as female, $13.1 \%$ as African American (Black), and $16.7 \%$ as Hispanic or Latino. African Americans and Hispanics are about 3 times lower than the national value, but females are almost 5 times lower. Because females are only $11.69 \%$ of Computer Science Bachelor degrees and the fact that they are showing a continuous decline in Computer Science, they are our biggest concern. African Americans and Hispanics are not declining, but we would still like to see their representation increase to mimic their national values.

\section{Study 2}

For our second study, we interviewed students that were not in the Computer Science field. The purpose of these interviews was to compare the findings with previous studies and to also look for new barriers. In total, 16 students were interviewed. Five were female high school students, five female college students, five male African American students, and two Hispanic male students.

We interviewed five female high school students about pursuing computer science degrees. One girl said she didn't think she would find the degree interesting. Another said that it didn't fit her interests and it seems really hard. A third girl said that she didn't understand computers. The fourth girl said that she prefers face to face communication and couldn't be in a technology driven field. The last girl interviewed said that the major seemed too challenging.

Female college students also showed a lack of interest in computer science. A few did say that computer science was a difficult major. One of the interviewed students also said that women weren't programmed to do computer science because she feels that it is male-oriented. Others have family members that are in computer science fields, but it didn't interest them. One student did mention that she had experience using scripts, but she didn't think it was interesting enough to make a career out of it.

We also interviewed five male African Americans and two Hispanic males that were not getting a computer science degree. The general consensus among the African Americans was that they didn't get into the field because they had 


\section{Issues in Information Systems \\ Volume 14, Issue 1, pp.143-152, 2013}

no experience to know if they would like it. One did take a Computer Science course in the past, but he thought it was difficult. When they chose a degree to pursue, they all decided to go with something that they were already familiar with. One Hispanic male looked at getting a computer science degree because one of his parents had done that, but he ultimately decided to take another path. The other Hispanic male thought the degree was worthless because anybody could acquire those skills at a technical school.

Through our interviews, we were able to verify some barriers that we had previously discovered. These barriers were as follows: lack of experience with computers, computers are difficult to use/understand, and computer science is better suited for males. Most of our responses dealt with how the interviewee had no interest in working with computers.

\section{Study 3}

Our last study is the survey we conducted. The total amount of respondents to our survey, thus far, was 70 students. The gender break down consisted of 14 male and 56 female. The race break down was 51 Caucasian, 8 African American, and 11 Hispanic. 90\% of our respondents were below the age of 26 with the majority (69\%) between the ages of 20 and 25. Business degrees (15) and Social Science degrees (15) were the most common degree pursued by our respondents.

Table 1. Demographic of Survey Respondents

\begin{tabular}{|l|c|c|l|c|c|}
\hline \multicolumn{3}{|c|}{ Gender } & \multicolumn{3}{c|}{ Race } \\
\hline Female & 56 & $80 \%$ & Black or African American & 8 & $11.4 \%$ \\
\hline Male & 14 & $20 \%$ & Hispanic or Latino & 11 & $15.7 \%$ \\
\hline \multicolumn{7}{|c|}{ Age } & White/Caucasian & 51 & $72.9 \%$ \\
\hline$<20$ & 15 & $21.4 \%$ & Applied Studies & 9 & $12.9 \%$ \\
\hline $20-25$ & 48 & $68.6 \%$ & Creative \& Performing Arts & 4 & $5.7 \%$ \\
\hline $26-29$ & 2 & $2.9 \%$ & Education \& Kinesiology & 7 & $10 \%$ \\
\hline $30-35$ & 3 & $4.3 \%$ & Natural Sciences \& Mathematics & 4 & $5.7 \%$ \\
\hline$>35$ & 2 & $2.9 \%$ & Social Sciences & 15 & $21.4 \%$ \\
\hline & Business & 15 & $21.4 \%$ \\
\cline { 2 - 6 } & Nursing & 6 & $8.6 \%$ \\
\cline { 2 - 6 } & Other & 7 & $10 \%$ \\
\cline { 2 - 6 }
\end{tabular}

A confirmatory factor analysis (CFA) was performed. The loading factors for the measurement items are listed in Table 3. Except for item AS2, all the other factors load at the suggested value of 0.6 or greater. Cronbach's alpha is greater than 0.70 except for area AS. These numbers suggest the survey is largely valid and reliable.

Table 2. Confirmatory Factor Analysis

\begin{tabular}{|c|c|c|c|c|c|c|c|}
\hline Area & $\begin{array}{c}\text { Cronbach's } \\
\text { Alpha }\end{array}$ & Items & $\begin{array}{c}\text { Factor } \\
\text { Loading }\end{array}$ & Area & $\begin{array}{c}\text { Cronbach's } \\
\text { Alpha }\end{array}$ & Items & $\begin{array}{l}\text { Factor } \\
\text { Loading }\end{array}$ \\
\hline \multirow[t]{3}{*}{ IM } & \multirow[t]{3}{*}{0.712} & IM1 & 0.816 & \multirow[t]{3}{*}{$\mathrm{CP}$} & \multirow[t]{3}{*}{0.928} & CP1 & 0.930 \\
\hline & & IM2 & 0.953 & & & $\mathrm{CP} 2$ & 0.929 \\
\hline & & IM3 & 0.919 & & & CP3 & 0.946 \\
\hline \multirow[t]{3}{*}{$\mathrm{EC}$} & \multirow[t]{3}{*}{0.954} & EC1 & 0.939 & \multirow[t]{3}{*}{ AS } & \multirow[t]{3}{*}{0.337} & AS1 & 0.764 \\
\hline & & EC2 & 0.975 & & & AS2 & 0.338 \\
\hline & & EC3 & 0.958 & & & AS3 & 0.853 \\
\hline \multirow[t]{3}{*}{$\mathrm{MC}$} & \multirow[t]{3}{*}{0.902} & MC1 & 0.861 & \multirow[t]{3}{*}{$\mathrm{AJ}$} & \multirow[t]{3}{*}{0.869} & AJ1 & 0.906 \\
\hline & & MC2 & 0.958 & & & $\mathrm{AJ} 2$ & 0.838 \\
\hline & & MC3 & 0.925 & & & $\mathrm{AJ} 3$ & 0.930 \\
\hline
\end{tabular}




\begin{tabular}{|c|c|c|c|c|c|c|c|}
\hline \multirow[t]{3}{*}{ GN } & \multirow[t]{3}{*}{0.914} & GN1 & 0.966 & \multirow[t]{3}{*}{$\mathrm{DC}$} & \multirow[t]{3}{*}{0.896} & $\mathrm{DC} 1$ & 0.868 \\
\hline & & GN2 & 0.969 & & & $\mathrm{DC} 2$ & 0.928 \\
\hline & & GN3 & 0.830 & & & DC3 & 0.935 \\
\hline \multirow[t]{3}{*}{ PP } & \multirow[t]{3}{*}{0.836} & PP1 & 0.905 & \multirow[t]{3}{*}{ BW } & \multirow[t]{3}{*}{0.941} & BW1 & 0.964 \\
\hline & & PP2 & 0.946 & & & BW2 & 0.942 \\
\hline & & PP3 & 0.751 & & & BW3 & 0.938 \\
\hline \multirow[t]{3}{*}{ MP } & \multirow[t]{3}{*}{0.889} & MP1 & 0.897 & & & & \\
\hline & & MP2 & 0.913 & & & & \\
\hline & & MP3 & 0.911 & & & & \\
\hline
\end{tabular}

The statistical technique we used to analyze the data is multiple linear regressions. We understand more robust statistical techniques (e.g. Structural Equation Modeling (SEM)) exist to analyze our data. However, we are undergraduate students and haven't been exposed to these techniques yet. In addition, our sample size is probably not large enough for SEM.

When using multiple linear regressions, there are four assumptions that are made. The assumptions are linearity, independence of errors, homoscedasticity, and normality. If any of these assumptions are violated the linear regression output could be misleading.

In the case of multiple linear regressions using gender, we check for linearity by plotting the residuals versus predicted values. Our data appears to be linear. We use the Durbin-Watson statistic for testing independence of errors. Our data produces a Durbin-Watson value of 1.950 which is within the acceptable range of 1.5 to 2.5 . This means that the assumption of independence of errors is satisfied. Testing homoscedasticity is similar to testing linearity, except we are looking for the variance to increase as the predicted value increases. The assumption of homoscedasticity seems to be satisfied. To test normality, we use a residual QQ plot. When viewing the plot, the distribution appears to be approximately normal.

In the case of multiple linear regressions using race, the residual versus predicted values plot shows our data to be reasonably linear. The Durbin-Watson value is 1.818 , which satisfies the independence of errors assumption. The assumption of homoscedasticity seems to be satisfied from the data collected. The residual QQ plot appears to be linear which means the distribution appears to be approximately normal.

The model for multiple linear regressions is:

$$
\mathrm{y}_{\mathrm{i}}=\beta_{0}+\beta_{1} \mathrm{x}_{\mathrm{i} 1}+\beta_{2} \mathrm{x}_{\mathrm{i} 2}+\ldots+\beta_{\mathrm{p}} \mathrm{x}_{\mathrm{ip}}+\mathrm{e}_{\mathrm{i}} \text { for } i=1,2, \ldots, \mathrm{n} .
$$

We split the file into two: one contains responses from white women, and the other includes records from minorities. After running the multiple linear regression (stepwise) model on white women, the ANOVA table suggests that we reject the null hypothesis that all slopes equal 0 (p-value $=0.002$ ), which means at least one of the variables is statistically significant. The t-tests on coefficients suggest MP (perception that computer science is better suited for males) is a statistically significant variable contributing to whether a student chooses to major in computer science ( $\mathrm{p}$-value $=0.002)$. The fitted regression line for our significant predictor is IM (intent to major in computer science) $=0.955+0.133(\mathrm{MP})$. The R-square for this model is .184 which means that MP explains $18.4 \%$ of the variation in IM.

Table 3. Multiple Linear Regression Coefficients for White Women

\begin{tabular}{|c|c|c|c|c|c|}
\hline & \multicolumn{2}{|c|}{ Unstandardized } & Standardized & & \\
\cline { 2 - 3 } & B & Std. Error & Coefficients (B) & T & Sig. \\
\hline (Constant) & .955 & .116 & & 8.209 & .000 \\
\hline MP & .133 & .040 & .429 & 3.292 & .002 \\
\hline
\end{tabular}




\section{Issues in Information Systems \\ Volume 14, Issue 1, pp.143-152, 2013}

After running the linear regression (stepwise) model on minorities, the ANOVA table suggests that we reject the null hypothesis that all slopes equal 0 ( $p$-value $=0.006$ ). The t-tests on coefficients suggest EC (experience with computers) and GN (perception that computers science is for geeks and nerds) are statistically significant variables contributing to whether a student chooses to major in computer science ( $\mathrm{p}$-value $=0.012$ and 0.038 for EC and GN respectively). The fitted regression line for the significant predictors is $\mathrm{IM}=0.797+0.136(\mathrm{EC})-0.221(\mathrm{GN})$. The R-square for this model is 0.473 which means that $\mathrm{EC}$ and GN explain $47.3 \%$ of the variation in IM.

Table 4. Multiple Linear Regression Coefficients for Minorities

\begin{tabular}{|c|c|c|c|c|c|}
\hline & \multicolumn{2}{|c|}{ Unstandardized } & Standardized & & \\
\cline { 2 - 3 } & $\mathrm{B}$ & Std. Error & Coefficients (B) & $\mathrm{T}$ & Sig. \\
\hline (Constant) & .797 & .772 & & 1.032 & .318 \\
\hline EC & .383 & .136 & .513 & 2.815 & .012 \\
\hline GN & -.221 & .098 & -.411 & -2.257 & .038 \\
\hline
\end{tabular}

In summary, our data appears to be a good fit for the linear regression model, the assumptions are satisfied, and we were able to find significant predictors for white women and minorities. The significant predictor for white women was MP and the significant predictors for minorities were EC and GN. None of the significant predictors seemed to be shared between gender and race.

\section{DISCUSSION}

The issue of women, African Americans, and Hispanics not joining computer science degrees is a really prominent issue in our society today. The percentage of women in computer science bachelor degree programs has dropped over $40 \%$ since the peak in 2000 which caused 2009 and 2010 to report the lowest percentages of women in computer science bachelor degrees in 18 years. The percentage of African Americans in computer science bachelor degree programs has remained fairly constant over the last eighteen years but they hold a lower percentage than women and Hispanics. From 1994 to 2008 the percentage of Hispanics in computer science bachelor degree programs has risen pretty steadily, but since 2008 the percentage has started to decrease. From our second study, the interviews, the main reason the women, Hispanic, and African American students gave for not pursuing the computer science degree was that they weren't interested in the degree. These same results were reiterated in our survey because the barriers we had were not agreed to by the students who took the survey as reasons why they didn't join the degree; they just weren't interested in the degree.

Previous studies that we researched gave ideas on how to increase the numbers of women and minorities in computer science major. One paper said that actions should be taken to form more positive perceptions of CS and the IT profession, and to increase interest in CS and self-confidence in computing skills [12]. Another paper said that "computer science courses and departments at all educational levels must be perceived as being more friendly to women" [1]. A focus group with computer science majors suggested that the following was implemented to recruit and maintain minorities: Recruitment visitations and course development with partnered high schools, Introduce pre-college preparatory programs (bridge programs), Increase scholarship opportunities, Increase availability of academic support to currently enrolled undergraduates [1].

The actions that the previous papers say to take to increase women and minority enrollment in computer science majors might produce results, but we think that the creating interest in the degree should be given the most concern. We have concluded that a lack of interest in the degree is the biggest issue because in our interviews the majority of the reasons given for not joining the computer science degree were that the interviewees were not interested in the major. Our survey found that the MP barrier had significant impact on the intent of white females to major in computer science. We also found that barriers EC and GN had significant impact on the intent of minorities to major in computer science. This means that out of our ten tested barriers only one was significant for white women and two for minorities. We feel that in addition to these identified significant barriers; lack of interest also was a barrier that influenced intent to major.

\section{CONCLUSIONS}




\section{Issues in Information Systems \\ Volume 14, Issue 1, pp.143-152, 2013}

We were interested in why women and minorities don't pursue the computer science degree. For our first study we analyzed data from the Taulbee Survey on the numbers of women, Hispanics, and African American in computer science bachelor degrees. For our second study we interviewed high school and college students on why they chose to not pursue the computer science degree. From these interviews we identified barriers that we could use in our survey. The third study was a survey that asked questions over barriers we identified from the interviews and from previous studies. From the interviews we gathered that the main reason the high school and college students weren't pursuing the computer science degree was due to a lack of interest in the degree. For women, we found perception that computer science is better suited for men as a significant barrier. For minorities (black and Hispanic), lack of computer experience and the perception that computer science is for geeks and nerds are the two significant barriers.

To further the research we have done on the topic, researchers could do studies to identify specifically why women and minority students aren't interested in the computer science degree by including questions about lack of interest in the interviews and survey instrument. Another thing that would improve our study would be to get more survey participants because a bigger sample size would give stronger results and would provide the ability to use more statistical techniques.

\section{REFERENCES}

1. Bunderson, E. D., \& Christensen, M. E. (1995). An Analysis of Retention Problems for Female Students in University Computer Science Programs.Journal of Research on Computing in Education, 28(1), 1-18.

2. Buzzetto-More, N., Ukoha, O., \& Rustagi, N. (2010). Unlocking the Barriers to Women and Minorities in Computer Science and Information Systems Studies: Results from a Multi-Methodolical Study Conducted at Two Minority Serving Institutions. Journal of Information Technology Education, 9.

3. Charleston, L. J. (2012). A qualitative investigation of African Americans' decision to pursue computing science degrees: Implications for cultivating career choice and aspiration.Washburn University Enrollment Report Fall 2012. Rep. N.p.: Office of Institutional Research, n.d. Print.

4. Coger, R. N., Cuny, J., Klawe, M., McGann, M., \& Purcell, K. D. (2012). Why STEM Fields Still Don't Draw More Women. Chronicle of Higher Education.

5. Computer Science Education Association. (2013) Key Facts About Computer Science . Retrieved from http://www.csedweek.org/key-facts

6. Cuny, J., \& Aspray, W. (2002). Recruitment and retention of women graduate students in computer science and engineering: results of a workshop organized by the computing research association. ACM SIGCSE Bulletin, 34(2), 168-174.

7. The Department for Professional Employees. (2012). DPE Fact Sheet 2012 - The STEM Workforce: An Occupational Overview. Retrieved from http://dpeaflcio.org/wp-content/uploads/The-STEM-workforce2012.pdf

8. Galpin, V. C., \& Sanders, I. D. (2007). Perceptions of computer science at a South African university. Computers \& Education, 49(4), 1330-1356.

9. Gose, B. (2012). A Reboot in Recruiting Women Into Computer Science. The Chronicle of Higher Education, 29

10. Gupta, U. G., \& Houtz, L. E. (2000). High school students' perceptions of information technology skills and careers. Journal of Industrial Technology, 16(4), 2-8.

11. National Center for Women \& Information Technology. (2013). By the Numbers. Retrieved from www.ncwit.org/bythenumbers

12. Papastergiou, M. (2008). Are computer science and information technology still masculine fields? High school students' perceptions and career choices.Computers \& Education, 51(2), 594-608.

13. Simard, Caroline (2009). Obstacles and solutions for underrepresented minorities in technology. Report for Anita Borg Institute for Women and Technology, Palo Alto, CA.Stine, Deborah D., and Christine M. Matthews. "The US science and technology workforce." Federal Publications (2009): 644.

14. Stoilescu, D., \& McDougall, D. (2011). Gender digital divide and challenges in undergraduate computer science programs. Canadian Journal of Education/Revue canadienne de l'éducation, 34(1), 308-333.

15. Stross, R. (2008). What has driven women out of computer science?. The New York Times, 16, 4. 


\section{APPENDIX A - Survey Instrument}

**All of the Following are ranked using scale 1 (Strongly Disagree) to 7 (Strongly Agree)

Intention to major in Computer Science

IM1. I would like to major in Computer Science.

IM2. I plan to major in Computer Science.

IM3. I intend to major in Computer Science.

\section{Experience with computers}

EC1. I consider myself a skilled computer user. [12]

EC2. As far as computers go, I feel competent. [12]

EC3. I am very confident in my ability to use computers. [12]

\section{Mentors in Computer Science}

MC1. I have a friend or family member in the Computer Science industry.

MC2. I know a successful person that has a Computer Science related degree.

MC3. I know someone with a Computer Science degree.

\section{Perception that the Computer Science degree is for geeks/nerds}

GN1. When I think of Computer Science degrees I think of geeks.

GN2. When I think of Computer Science degrees I think of nerds.

GN3. Computer Science is for geeks and nerds.

Perception that the Computer Science degree is mainly programming

PP1. Computer Science involves mainly programming. [8]

PP2. Computer Science degrees deal mostly with programming.

PP3. Programming is closely related to Computer Science.

\section{Perception that the Computer Science degree is better suited for men}

MP1. Computer Science is a science more appropriate for men than for women. [12]

MP2. Men are more likely to succeed in the IT profession than women. [12]

MP3. Men are by nature more inclined towards Computer Science than women. [12]

\section{Perception that the Computer Science degree is better suited for Caucasians}

$\mathrm{CP} 1$. Computer Science is a science more appropriate for Caucasians than for minorities. 


\section{Issues in Information Systems}

Volume 14, Issue 1, pp.143-152, 2013

CP2. Caucasians are more likely to succeed in the IT profession than minorities.

CP3. Caucasians are by nature more inclined towards Computer Science than minorities.

Availability of Scholarships in Computer Science degree

AS1. I have not heard about Computer Science scholarships at my college/university.

AS2. Availability of Computer Science scholarships influenced whether or not I would join the degree.

AS3. Computer Science scholarships are hard to get.

Availability of jobs in Computer Science field

AJ1. There are many jobs for people who have studied Computer Science. [8]

AJ2. There are interesting jobs available in Computer Science.

AJ3. There are good jobs available for people with Computer Science degrees. [8]

\section{Difficulty of the Computer Science major}

DC1. Computers are far too complicated for me. [12]

DC2. I think the Computer Science major is too difficult.

DC3. I would not succeed in the Computer Science degree because it is too difficult.

\section{Balance of work and life in Computer Science field}

BW1. Computer Science majors require too much time at work.

BW2. Computer Science degrees are too time demanding.

BW3. Computer Science degrees restrict too much free time. 